Papers and Originals

\title{
Combination Chemotherapy in Generalized Hodgkin's Disease
}

\author{
W. M. NICHOLSON, ${ }^{*}$ M.B., B.SC., M.R.C.P. ; M. E. J. BEARD, † M.R.C.P., M.R.C.PATH. \\ D. CROWTHER, $\ddagger$ PH.D., M.R.C.P. ; A. G. STANSFELD, $\$ M.B., B.CHIR., F.R.C.PATH. \\ C. P. VARTAN, $\|$ M.B., B.S., M.R.C.P. ; J. S. MALPAS, $\mid$ D.PHIL., M.R.C.P. \\ G. HAMILTON FAIRLEY,** D.M., F.R.C.P. ; SIR RONALD BODLEY SCOTT,†† k.C.v.o., D.M., F.R.c.P.
}

Summary: Fifty-two patients with generalized Hodgkin's disease were treated with a combination of mustine hydrochloride, vinblastine, procarbazine, and prednisolone. Complete remissions were obtained initially in six out of seven patients $(86 \%)$ who had previously received no treatment, in 15 out of $19(79 \%)$ who had had only radiotherapy in the past, and in 9 out of $26(35 \%)$ who had previously been given chemotherapy with or without radiotherapy. Of these 30 patients in whom a complete remission was obtained 22 have been free of any symptoms or signs of disease for periods ranging from 4 to 22 months. The response to treatment was rapid, and toxicity was not a major problem, except in those who had previously been treated with cytotoxic drugs used continuously and not in courses. A comparative trial of radiotherapy and combination therapy in the treatment of Stage III Hodgkin's disease is strongly recommended.

\section{Introduction}

There is now no doubt that patients with localized Hodgkin's disease should be treated with intensive wide-field radiotherapy. Indeed most of these patients may be cured if this is done (Peters and Middlemiss, 1958; Easson, 1966; Kaplan, 1966; Peters et al., 1966). At the time of presentation, however, some patients have disseminated disease and others have recurrence in previously irradiated areas, making further radiotherapy impossible, and it is in these circumstances that chemotherapy may prove extremely valuable.

Until recently we used the effective drugs, such as the nitrogen mustards (mustine hydrochloride, chlorambucil, cyclophosphamide), vinblastine, and procarbazine, as single agents. We found that definite objective improvement occurred in about $70 \%$ of the patients (Fairley et al., 1966). Lacher and Durant (1965), however, using a combination of vinblastine and chlorambucil, obtained complete remissions in $63 \%$ and partial remissions in a further $18 \%$ of patients with disseminated Hodgkin's disease. At the National Cancer Institute, Bethesda, Carbone and his colleagues (Perry et al. 1967; De Vita et al., 1969), using four agents simultaneouslyprednisone, vincristine, nitrogen mustard, and procarbazine-

* Late House-physician, St. Bartholomew's Hospital, London E.C.1. † Research Fellow in Medicine (Haematology), New England Medica Center, Boston, Massachusetts.

¥ Registrar in Medicine, St. Bartholomew's Hospital, London EC.1.

Senior Lecturer and Consultant in Morbid Anatomy, St. Bartholomew's Hospital, London E.C.1.

Registrar in Medicine, St. Bartholomew's Hospital, London E.C.1 9 Senior Lecturer in Medicine, St. Bartholomew's Hospital, London E.C.1.

* Consultant Physician, St. Bartholomew's Hospital, London E.C.1

t+ Senior Physician, St. Bartholomew's Hospital, London E.C.1. obtained $80 \%$ complete remissions and $90 \%$ complete plus partial remissions in patients with Hodgkin's disease who had previously received no treatment. Similar results were obtained by Bernard and his colleagues in Paris (Bernard $e t$ al., 1967; Goguel et al., 1969). Because these results were so much better than those obtained with single agents, we have been using combination chemotherapy for the past two years. The purpose of this paper is to record our results and to discuss their significance.

\section{Patients and Methods}

The diagnosis was established by histological examination of biopsy material in all the patients and classified by a slight modification of the classification of Lukes and Butler (1966) as shown in Table I. The extent of the disease was assessed immediately before combination chemotherapy by clinical examination, chest $x$-ray films including hilar tomography, lymphangiography, aspiration bone marrow biopsy, and liver function tests; in some patients liver scan and liver biopsy were also carried out. The patients were then classified according to the Rye staging (Peters et al., 1966): stage I, disease limited to one anatomical region; stage II, disease confined to one side of the diaphragm; stage III, disease on both sides of the diaphragm but limited to involvement of lymph nodes, spleen, and Waldeyer's ring; and stage IV, involvement of bone marrow, lung, pleura, liver, bone, skin, kidneys, gastrointestinal tract, or any tissue other than lymph nodes, spleen, or Waldeyer's ring.

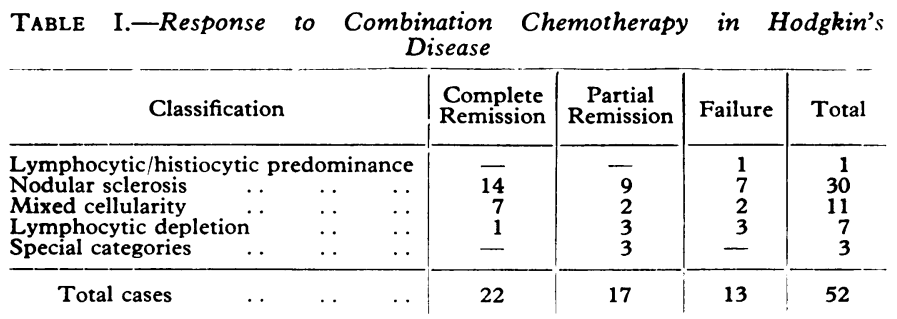

If the systemic symptoms of fever, sweating, pruritus, and loss of weight were absent the patients were classified as " $\mathrm{A}$ " and if present as "B." Table II shows the number of patients with each stage included in this study. Most of the patients had stage III and IV disease, and the only reason any stage II patients were included is because there was a recurrence in an area previously treated with inadequate radiotherapy many years before. Our regimen has changed slightly in detail, but not in principle, from that used at the National Institute of Health (Perry et al., 1967) and by Bernard et al. 
(1967). Their regimen consists of six courses, each lasting two weeks, with two weeks' rest between each course:

Prednisone* $40 \mathrm{mg}$./sq. $\mathrm{m}$. daily by mouth on Days 0-14 inclusive.

Procarbazine $100 \mathrm{mg} . / \mathrm{sq}$. m. daily by mouth on Days $0-14$ inclusive.

Vincristine $1.4 \mathrm{mg} . / \mathrm{sq} . \mathrm{m}$. on Days 0 and 7.

Mustine hydrochloride $6 \mathrm{mg} . / \mathrm{sq}$. m. on Days 0 and 7.

TABLE II.-Response to Combination Chemotherapy in Hodgkin's

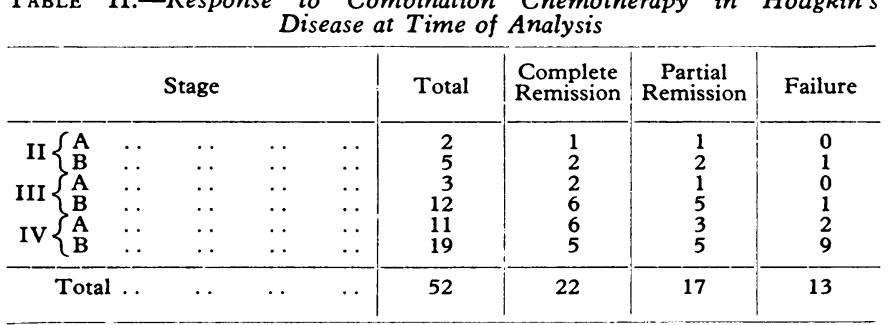

We have made three modifications. Firstly, we have not used such a large dose of prednisone because on this dose two patients became psychotic, but have given our reduced dose with every course. Secondly, we have used vinblastine rather than vincristine because vinblastine is known to be very effective when used as a single agent in Hodgkin's disease and is less neurotoxic than vincristine. Thirdly, we have lengthened the time interval between courses from two to four weeks. Our regimen is as follows:

Prednisolone $40 \mathrm{mg}$. (for an adult patient) daily by mouth on Days 0 - 14 inclusive.

Procarbazine $100 \mathrm{mg}$./sq. m. daily by mouth on Days 0-14 inclusive.

Vinblastine $10 \mathrm{mg}$. (for an adult patient) intravenously on Days 0,7 , and 14

Mustine hydrochloride $6 \mathrm{mg}$./sq. m. on Days 0 and 7.

In this series 52 patients were treated exclusively with our regimen. Three were initially treated with the regimen of Carbone (Perry et al., 1967), but after receiving two courses they were changed to our regimen.

The two essential aims in using chemotherapy in disseminated Hodgkin's disease are, firstly, to produce complete or, failing this, partial remissions; and, secondly, to maintain these remissions for as long as possible. De Vita et al. (1969) showed that even if complete remissions were obtained with six courses of combination chemotherapy, and no further treatment was given, relapses occurred. It is therefore now our policy to give six courses of treatment, leaving four weeks between each course. If at the end of this time there are still signs of disease, further courses are given, preferably at monthly intervals; or if the patients are completely unresponsive, other agents such as 1,3-bis-( 2 chloroethyl)-1-nitrosourea or bleomycin are used. Patients who are in complete remission after their first six courses are then given courses at three-monthly intervals for one year and at four-monthly intervals for the next year.

The definition of complete and partial remission is difficult. We therefore have three categories.

(1) Complete Remission (apparently free from disease).-This means the absence of all detectable disease on clinical examination, chest radiography (including tomography), rescreening of the abdomen in cases where sufficient dye remains after previous lymphangiography, and the return of liver function tests to normal. In addition there must be complete relief of systemic symptoms.

(2) Partial Remission.-Objective improvement in the size of glandular masses, hepatosplenomegaly, or infiltrations elsewherefor example, bone or lung-with or without relief of systemic symptoms.

(3) Active Disease.-Progression of the disease.

*Given only with the first and fourth courses.

\section{Results}

The results are summarized in the Charts, in which the patients have been divided into three groups: those who had never been treated before-that is, the disease was stage III or IV at the time of presentation; those who had received only radiotherapy; and those who had previously received chemotherapy with or without radiotherapy. The number of patients achieving complete remission at some time during their treatment, and the response at the time of analysis, are summarized in Table III.

\begin{tabular}{|c|c|c|c|c|c|}
\hline III.-Response & to & $\begin{array}{c}\text { Combination } \\
\text { Disease }\end{array}$ & Chemotherd & apy & odgkin's \\
\hline \multirow{2}{*}{ Group } & \multirow{2}{*}{ Total } & \multirow{2}{*}{$\begin{array}{c}\text { No. Achieving } \\
\text { Complete } \\
\text { Remission at } \\
\text { Some Time in } \\
\text { their Treatment }\end{array}$} & \multicolumn{3}{|c|}{$\begin{array}{l}\text { Response at Time } \\
\text { of Analysis }\end{array}$} \\
\hline & & & $\begin{array}{l}\text { Complete } \\
\text { Remission }\end{array}$ & $\begin{array}{c}\text { Partial } \\
\text { Remission }\end{array}$ & Failure \\
\hline \multirow{3}{*}{$\begin{array}{l}\text { No previous treatment.. } \\
\text { Only radiotherapy in the } \\
\text { past . } \\
\text { Chemotherapy with or } \\
\text { without radiotherapy }\end{array}$} & 7 & $6(86 \%)$ & $5(71 \%)$ & 1 & 1 \\
\hline & 19 & $15(79 \%)$ & $12(63 \%)$ & 5 & 2 \\
\hline & 26 & $9(35 \%)$ & $5(19 \%)$ & 11 & 10 \\
\hline Total & 52 & 30 & 22 & 17 & 13 \\
\hline
\end{tabular}

Of the seven patients who had not received any previous treatment a complete remission was obtained in six, of whom five are still without evidence of disease from 2 to 20 months after the onset of combination chemotherapy. Unfortunately, in one patient the complete remission was short-lived, and she died 16 months after the beginning of chemotherapy (Case 47). The remaining patient is in partial remission 21 months after beginning treatment, and the only evidence of activity is a raised serum alkaline phosphatase, which could in fact be due to chronic biliary obstruction following surgery to the gall bladder, and not Hodgkin's disease (Case 48).

Of the 19 patients who had received only radiotherapy in the past 15 went into complete remission and 12 are still without evidence of disease 4 to 18 months after the onset of combination chemotherapy. Of the remaining three, two are dead-one (Case 29) died from bronchopneumonia between the sixth and seventh courses of combination chemotherapy, and at necropsy there was no evidence of Hodgkin's disease; the other (Case 36) died between the second and third courses of treatment from bronchopneumonia, generalized herpes zoster, and acute polyneuritis. At the time this occurred his blood count was normal, and the overwhelming infection could not be attributed to bone marrow failure or to the lack of circulating immunoglobulins or lymphocytes, as these were all normal.

Twenty-six patients had previously received chemotherapy which had been given as single agents used in a continuous manner with or without previous radiotherapy. When treated with combination chemotherapy, nine obtained a complete remission and five are still without evidence of disease between 5 and 10 months later; of the four who subsequently relapsed two are in partial remission and two have died from their disease. Partial remissions occurred at some time in 19 patients, and 11 are still under control but with evidence of disease 5 to 19 months later. Ten patients in this group have died, four having failed to respond at all to chemotherapy.

The initial response may be analysed in other ways. Table I shows the initial response to combination chemotherapy in patients classified according to the histological type at the time of diagnosis. It is difficult to draw any definite conclusions, as most of the patients had nodular sclerosing Hodgkin's disease, but clearly complete remission may be obtained in all types of disease and the initial histological appearance is therefore not relevant when deciding whether chemotherapy should be given. Indeed, despite the great advances in the classification of this disease made by Lukes and Butler (1966) there are still difficulties, as illustrated by our miscellaneous group in Table I. There were three patients 
Patients who have had previous chemotherapy with or without radiotherapy

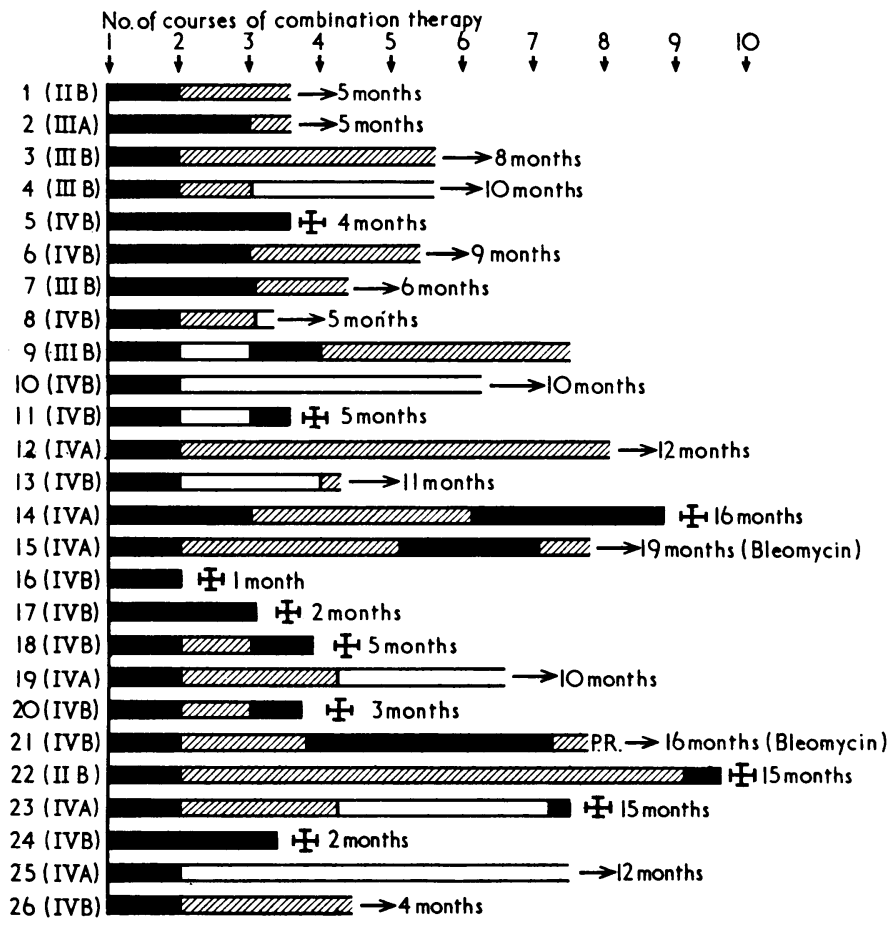

Patients who have had radiotherapy_previously
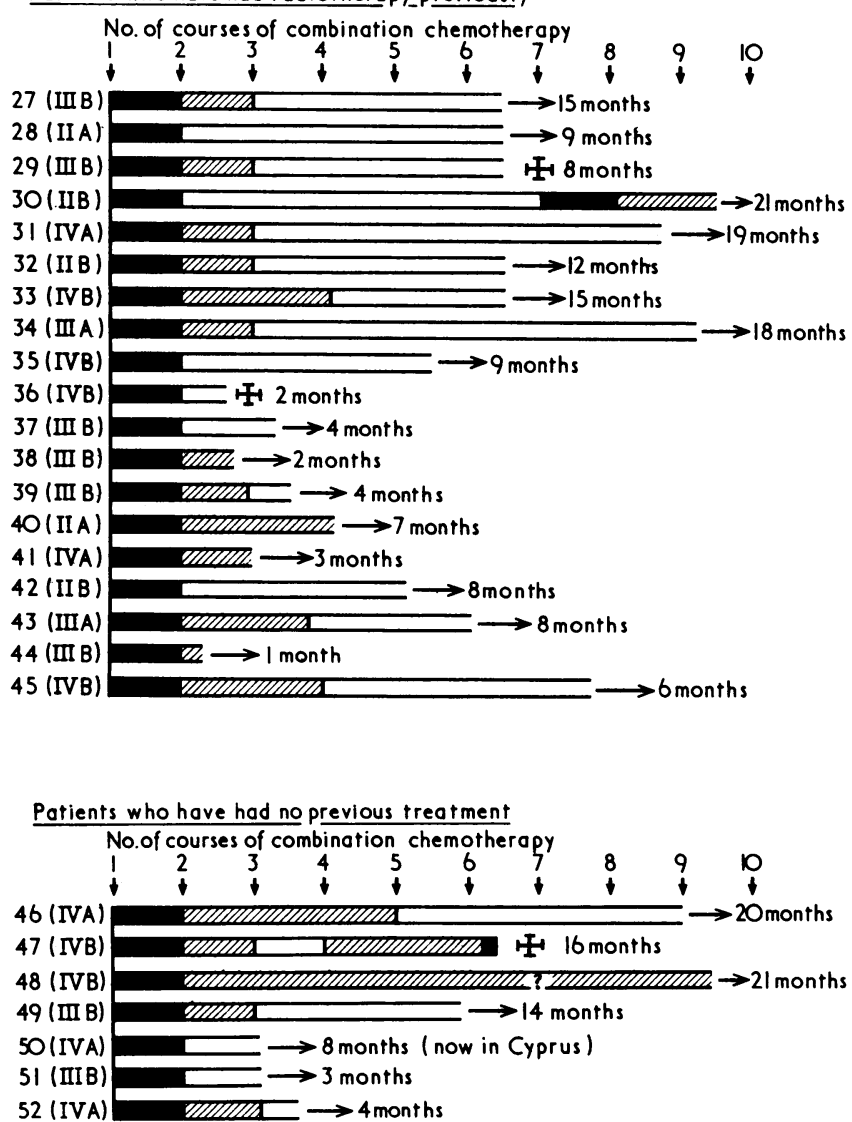

The course of the disease in 52 cases is represented diagrammatically, starting on the left. The solid area represents absence of remission or relapse. The shaded area indicates partial remission and the unshaded area complete remission. A cross represents death of the patient. The duration of therapy is given in months on the right. Full assessments were carried out before each course of chemotherapy, which is indicated by numbered arrows. P.R. in Case $21=$ partial remission. in this group: the first had Hodgkin's disease arising in the stomach and was difficult to classify histologically; the second had a lymphocytic-predominant picture with large bizarre reticulum cells but no classical Reed-Sternberg cells, and one of us (A.G.S.) thought this was best classified as Hodgkin's disease; and their third showed different histological patterns at different sites, the mediastinal lymph node biopsy showing nodular sclerosis, and the cervical lymph node biopsy showing mixed cellularity, despite the fact that these two biopsies were taken at the same time.

The correlation between the stage of the disease and the initial response to combination chemotherapy is shown in Table II. The only patients who failed to respond at all were four with stage IVB disease. Table IV shows the correlation between the initial response and the presence of systemic symptoms; the response, as expected, being much better in those without symptoms.

TABLE IV.-Response to Combination Chemotherapy in Hodgkin's

\begin{tabular}{|c|c|c|c|c|}
\hline Group & Total & $\begin{array}{l}\text { Complete } \\
\text { Remission }\end{array}$ & $\begin{array}{c}\text { Partial } \\
\text { Remission }\end{array}$ & Failure \\
\hline $\begin{array}{l}\text { A. Patients with no systemic symptoms } \\
\text { B. Patients with systemic symptoms .. }\end{array}$ & $\begin{array}{l}16 \\
36\end{array}$ & $\begin{array}{r}9 \\
13\end{array}$ & $\begin{array}{r}5 \\
12\end{array}$ & $\stackrel{2}{11}$ \\
\hline $\begin{array}{llll} & \ldots & \ldots & \ldots\end{array}$ & 52 & 22 & 17 & 13 \\
\hline
\end{tabular}

\section{Toxicity}

In general, patients have tolerated this form of combination chemotherapy extremely well, and indeed no patient has refused to have a further course. There are several reasons for this: firstly, the relief of symptoms is very rapid, probably due to intravenous nitrogen mustard on the first day of treatment. Secondly, the toxic effects have been less than anticipated, and are exactly what one would expect. Injection of mustine hydrochloride causes nausea and vomiting unless preceded by chlorpromazine, and for this reason the patients remain in hospital the night after the injection. Occasionally nausea and vomiting occur with procarbazine, but this is usually readily controlled by oral perphenazine. It is important that the time spent in hospital during each course is short, and the patients have only two overnight admissions in each 14-day course (on Day 0 and Day 7). The injection of vinblastine on Day 14 is given as an outpatient. Courses are of ten arranged at weekends, so that patients can continue their work uninterrupted. Neurological complications are not seen with the dose of vinblastine used in our regimen, though peripheral neuropathy is common if vincristine is used. The features of Cushing's syndrome are negligible when prednisolone is used in this intermittent fashion.

The major toxic effect is, of course, on the bone marrow. Severe depression of the white blood count may occur, particularly in patients who have had previous chemotherapy. It is for this reason that we lengthen the time interval between courses from two to four weeks, and in some patients even longer, provided they are in remission. Our aim was to give as complete a course as possible at longer intervals, rather than to adhere rigidly to a time schedule and to be forced to give inadequate dosage. Depression of bone marrow activity was more pronounced in patients who had previously had chemotherapy. Indeed it proved irreversible in five patients who died. These patients, however, had had prolonged courses of cyclophosphamide, vinblastine, or procarbazine before being treated with combination chemotherapy. Transient episodes of leucopenia and thrombocytopenia have occurred after combination chemotherapy in patients who had never received chemotherapy in the past. These, so far, have always recovered after a variable period of up to eight weeks, and in no patients have we had to stop treatment.

It is essential to keep a close watch on the blood counthaemoglobin, white cell count, and platelets-and this is done 
on Days 0,7 , and 14 in each course. Doses of drugs given may have to be modified accordingly. It is our experience that anaemia, leucopenia, and thrombocytopenia occur more often as the number of courses given increase. The interval between courses is lengthened to three months after six courses to prevent undue bone marrow depression.

\section{Discussion}

From these results and from those reported from the U.S.A. (De Vita et al., 1969; Goguel et al., 1969) there can be no doubt that combination chemotherapy produces a higher proportion of both complete and partial remissions than the use of single agents in generalized Hodgkin's disease. Furthermore, the response to treatment is more rapid than with single agents, and the time interval between each course probably gives the normal tissues, particularly the bone marrow, an opportunity to recover, enabling more chemotherapy to be given. We still do not know whether remissions obtained in this way will last longer than when single agents are used, but the results of De Vita et al. (1969) suggest that they may.

Our results show that the bone marrow toxicity of combination chemotherapy is much greater in patients who have previously received continuous treatment with single cytotoxic agents, and such therapy should be given with caution to such patients, probably in modified doses. With patients who have had no previous chemotherapy it has been gratifying that the leucopenia and thrombocytopenia have always resolved. The reason that we encountered more marrow toxicity than did De Vita et al. (1969) and Goguel et al. (1969) is probably because we used vinblastine rather than vincristine, but we felt that this disadvantage was outweighed by the absence of neurotoxicity in our regimen.

These results raise another and very important problem in the treatment of Hodgkin's disease-that is, the indication for using chemotherapy as opposed to radiotherapy. Everyone is now agreed that stage I and stage II disease must be treated with high-dosage large-field irradiation, and that stage IV disease should be treated with chemotherapy. The problem centres on the treatment of patients with stage III disease. Smithers (1969) recommended treating with radiotherapy patients having stage IIIA disease, and Kaplan (1968) included IIIB as well. Others are still treating stage III disease with chemotherapy. Certainly the initial response to combination chemotherapy in those patients in whom chemotherapy is being used for the first time compares very favourably with that of Kaplan's patients treated with radiotherapy, but it remains to be seen which group will have the better ultimate prognosis. A controlled trial of the two forms of treatment in stage III is highly desirable.

We wish to thank Dr. Paul P. Carbone and his colleagues of the National Cancer Institute, Bethesda, for introducing us to their combination chemotherapy regimen in Hodgkin's disease; Dr. W. I. H. Shedden, of Eli Lilly \& Co. Ltd., for generous financial support; and Mr. P. J. Cull and Mr. W. D. Tredinnick, of the department of medical illustration, St. Bartholomew's Hospital.

Requests for reprints should be sent to Dr. G. Hamilton Fairley.

\section{REFERENCES}

Bernard, J., et al. (1967). Presse Médicale, 75, 2647.

De Vita, V. T., Serpick, A., and Carbone, P. P. (1969). Proceedings of the American Association for Cancer Research, 10, 19.

Easson, E. C. (1966). Cancer (Philadelphia), 19, 345.

Fairley, G. H., Patterson, M. J. L., and Scott, R. B. (1966) British Medical fournal, 2,75

Goguel, A., Weil, M., Jacquillat, $\mathrm{Cl}$, and Boiron, M. (1969), In Actualités Hématologiques, ed J. Bernard, 3rd series, p. 124. Paris, Masson.

Kaplan, H. S. (1966). Cancer (Philadelphia), 19, 356

Kaplan, H. S. (1968). New England fournal of Medicine, 278, 892

Lacher, M. J., and Durant, J. R. (1965). Annals of Internal Medicine, 62,468

Lukes, R. J., and Butler, J. J. (1966). Cancer Research, 26, 1063.

Perry, S., Thomas, L. B., Johnson, R. E., Carbone, P. P., and Haynes, H. A. (1967). Annals of Internal Medicine, 67, 424.

Peters, M. V., Alison, R. E., and Bush, R. S. (1966). Cancer (Philadelphia), 19, 308 .

Peters, M. V., and Middlemiss, K. C. H. (1958). American foumal of Roentgenology, Radium Therapy and Nuclear Medicine, 114.

Smithers, D. W. (1969). Clinical Radiology, 20, 124.

\footnotetext{
Senior Registrar in Anaesthetics, Department of Clinical Investigation, Dudley Road Hospital, Birmingham 18.

† Professor of Anaesthetics, University of Birmingham.

\# Consultant Anaesthetist, and Consultant to the Department of Clinical Investigation and Research, Dudley Road Hospital, Birmingham 18.
}

\section{Introduction}

There appears to be a continuing demand for sedation or general anaesthesia for conservative dentistry, but to what extent this is due to publicity which has not indicated adequately the hazards involved is still not clear (Central Health Services Council, 1967). It seems likely that the safest and most satisfactory method of meeting this demand will be in the use of potent but short-acting tranquillizers rather than anaesthetics. Clinical reports on the use of intravenous diazepam for this purpose have already been published (Poswillo, 1967; Healy, Edmondson, and Hall, 1970; MacDonald and Carmichael, 1970). Though a report of the cardiovascular and respiratory effects of diazepam has been published (Dalen et al., 1969) 